\title{
Space Charge Behavior in Multi-layer Oil-paper Insulation under Different DC Voltages and Temperatures
}

\author{
Chao Tang ${ }^{1,2}$, G. Chen ${ }^{2}$, M. Fu ${ }^{3}$ and Rui-jin Liao ${ }^{1}$ \\ ${ }^{1}$ The State Key Laboratory of Power Transmission Equipment \& System Security and New Technology \\ Chongqing University, China \\ ${ }^{2}$ School of Electronics and Computer Science \\ University of Southampton, UK \\ ${ }^{3}$ AVERA T\&D Technology Centre, Stafford, UK
}

\begin{abstract}
Oil-paper as a reliable insulation system is widely used in power transformers and cables. The dielectric properties of oil-paper insulation play an important role in the reliable operation of power equipment. However, the formation and dynamics of space charge can affect the performance of insulation material. In this paper, space charge in oil-paper insulation system has been investigated using the pulsed electroacoustic (PEA) technique. A series of measurements were carried out when the insulation system was subjected to different applied voltages at different temperatures. Charge behavior in the insulation system has been analyzed and the influence of temperature on charge dynamics was discussed. The test results show that homocharge injection takes place under all the test conditions, the applied dc voltage mainly effect the amount of space charge, while the temperature has greater influence on the distribution and mobility of space charge inside oil-paper samples.
\end{abstract}

Index Terms - Space charge, oil-paper, DC voltage, multi-layer, pulsed electroacoustic (PEA).

\section{INTRODUCTION}

OIL-PAPER insulation has been used in power transformers, power cables and HVDC equipments for quite a long time because of its low cost and desirable physical and electrical properties. But it degrades under a combined stress of thermal, electrical, mechanical, and chemical stresses during routine operations. This will affect the lifetime of power equipment significantly. On the other hand, space charge in dielectric materials has a close relation to the electrical performance of a material. For example, trapped or low-mobility electrically charged species within the bulk can give rise to space charge, resulting in localized electrical stress enhancement. This can cause further concentration of charge and lead to premature failure of the material $[1,2]$. Therefore, a better understanding of charge dynamics, in accordance with the specific variation of the charge distribution in multi-layer insulation system becomes increasingly important and needs a careful investigation.

The pulsed electroacoustic (PEA) technique was first developed in 1980s, it has been widely used in space charge research area because of its low cost and ease of implementation. The PEA method can allow space charges to be observed during

Manuscript received on 30 March 2009, in final form 27 October 2009. poling, i.e. under electric field, and after electric field removal, i.e. during depolarization, thus providing thorough information on space charge dynamics [3]. Such method opens a way to understand physical processes taking place inside the dielectric materials, and makes it possible to select materials and interfaces which minimize the risks of breakdown in HV applications.

Most of the space charge measurements have been carried out upon polymeric insulating materials, such as XLPE, LDPE and PE. From the year 1997, a few studies have been performed on oil-paper insulation. Morshuis and Jeroense [4, 5] made some space charge tests on oil impregnated insulation paper, concluded from the test results that whatever the combination of paper and oil, three general trends were observed. Firstly, homocharge is always observed, both at the anode and the cathode. Secondly, specific charge growth/decay pattern occurs. Thirdly, the growth and decay of the charge profiles can be described by roughly two time constants. This is the first time that results have been published on space charge measurements on HVDC cable paper insulation [4, 5]. However, the influence of temperature has not been discussed. Ciobanu et al, analyzed the space charge evolution in oil-paper insulation, and associated the mobility phenomena with the mineral content of cable paper. They concluded that the charges parameters derived from the 
PEA measurements, such as, charge density, apparent trapcontrolled mobility and variation of trap depth distribution, can be successfully used towards promoting criteria for the best choice of oil-paper insulation technology for dc cables application [6].

In this paper, based on the PEA technique, a series of measurements were carried out when the oil-paper insulation system was subjected to different applied voltages and temperatures. Charge dynamics in the insulation system during the volts-on, volts-off and decay have been analyzed, and the influence of temperature on charge dynamics discussed.

\section{EXPERIMENTS}

In this study, the measurements were carried out on oil immersed insulation paper. The insulation paper which is made by Croylek Ltd., has a thickness of $\sim 60 \mu \mathrm{m}$ for single layer. The parameters of the paper meet the international standard IEC 554.2.

The insulation oil used in this experiment was Nytro 10X transformer oil, which was provided by Nynas Oil Company. Nytro 10X is an inhibited transformer oil with good electrical properties and oxidation stability, it has a widely industrial application as well.

Before PEA tests, several pretreatment steps were carried out upon samples. Firstly, the new insulation paper was cut into round shape with a diameter of $\sim 2 \mathrm{~cm}$. Then the paper samples were kept in a vacuum oven at $393 \mathrm{~K}\left(120^{\circ} \mathrm{C}\right)$ for $30 \mathrm{~min}$, in order to make the moisture content less than $0.2 \%$. After that, the paper samples were impregnated by fresh degassed insulation oil in a sealed oven. As thin paper was used, the sample can be fully impregnated after 1 day. All oil-paper samples used in these tests are thought to be uniform as that both the oil and paper sample are in the same size respectively, and the same pre-treatment are performed.

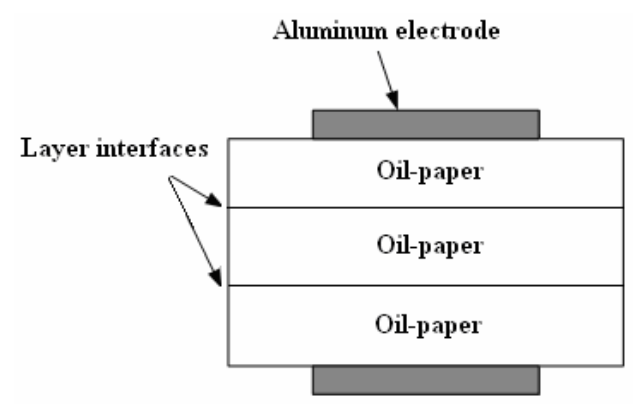

Figure 1. Schematic diagram of sample arrangement.

In practical application, oil-paper is usually used as multilayer insulation. Therefore, in this experiment, the PEA tests are performs on three layers oil-paper samples $(\sim 120 \mu \mathrm{m}$ after oil immersed and being pressed by electrodes, in Figure 1). The samples were stressed at three different dc voltage levels $(4 \mathrm{kV}, 6$ $\mathrm{kV}, 8 \mathrm{kV})$ and three temperatures $\left(20^{\circ} \mathrm{C}, 40{ }^{\circ} \mathrm{C}, 60^{\circ} \mathrm{C}\right)$. Each time, an electrical stress time of $1 \mathrm{~h}$ was tested. In addition, space charge evolution after the removal of the applied electric field was also measured.

The space charge measurements were taken at various times during the periods of both volts-on and volts-off (short-circuit condition) using the PEA technique (Figure 2). In the PEA technique, acoustic pressure waves are generated due to the interaction of pulsed electric field and charge layer. Detection of acoustic pressure waves allows one to determine charge distribution across the sample. The principle of the PEA can be seen in many literatures $[7,8]$. The PEA system (PEANUT, made by Five Lab) used in this study has a pulse width of 5 ns. The bottom electrode is made of $10 \mathrm{~mm}$ thick aluminum plate and the top electrode is semiconducting polymer to achieve a better acoustic match. The piezoelectric sensor used was a $9 \mu \mathrm{m}$ thick $\mathrm{LiNbO} 3$ material that enables the system to be heated up to $90{ }^{\circ} \mathrm{C}$ although this was not utilized in the present study.

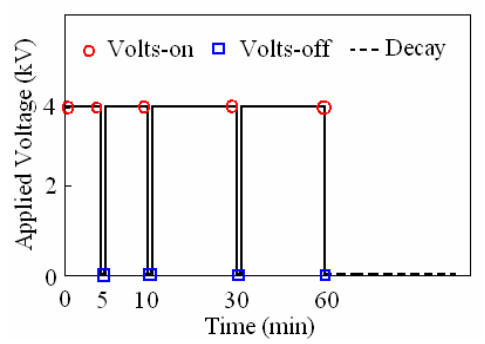

Figure 2. Illustration of experimental measurement points.

\section{RESULTS AND DISCUSSION}

\subsection{STEP VOLTAGE TEST}

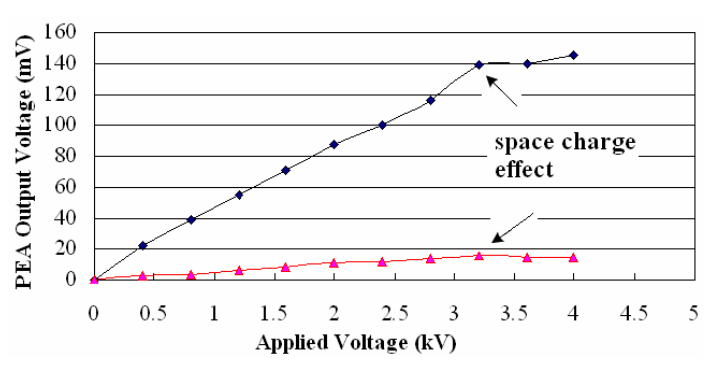

Figure 3. Step voltage test (under $20^{\circ} \mathrm{C}$ ).

First, a step voltage test was conducted to determine the threshold voltage/stress at which the space charge effect is initiated in the samples [9]. The amplitude of charge peaks on both the anode (red line) and the cathode (dark line) were recorded. As seen from Figure 3, the homocharges initiate when the applied voltage is about $3.2 \mathrm{kV}$ (under $20^{\circ} \mathrm{C}$ ). It indicates that no obvious space charge should exist in oil-paper sample below this level, at least for a short period of voltage applied. Hence a suitable signal measured at $2 \mathrm{kV}$ was selected as a calibration signal [10].

It is noteworthy that both the applied voltage and pulse voltage make a contribution to the output signal. The contribution from the pulse voltage is often neglected. Based on the study in paper [10], under the combination of an applied voltage of $10 \mathrm{kV}$ and a pulse voltage of $100 \mathrm{~V}$, the error introduced by neglecting the 
pulse voltage is only $0.35 \%$. As we are mainly focused on the dynamics process of space charge, the influence caused by the pulse is not taken into consideration in this paper.

\subsection{PEA TESTS AT $20^{\circ} \mathrm{C}$ \\ 3.2.1 VOLTS-ON}

It is obvious from the space charge distributions shown in Figure 4, the cathode peak is sharp and evident; in contrast, the anode peak is wide and flat, this is because of attenuation and scattering of acoustic wave caused by the oil-paper sample. Together with volts-off figures, the positions of electrodes were confirmed and marked with black lines.

As shown in Figures $4 \mathrm{a}, 4 \mathrm{~b}$ and $4 \mathrm{c}$, the peak value at electrodes increases with the applied voltage from $4 \mathrm{kV}$ to $8 \mathrm{kV}$. Under each applied voltage, because of homocharges injection at both electrodes, quantities of electric charges on both electrodes decreases as the stressing time increases. The positive charges accumulate in the vicinity of the anode, while the negative charges adjacent to the cathode. Charge injected quickly after voltage was switched on, an approximate equilibrium between positive and negative charge injection was observed after $30 \mathrm{~min}$. No big difference noticed after that time. However, it has been reported that it may take a relatively long period (e.g. up to 10000 s), to reach the stable regime, i.e. the equilibrium between charge injection, extraction and transport [9].

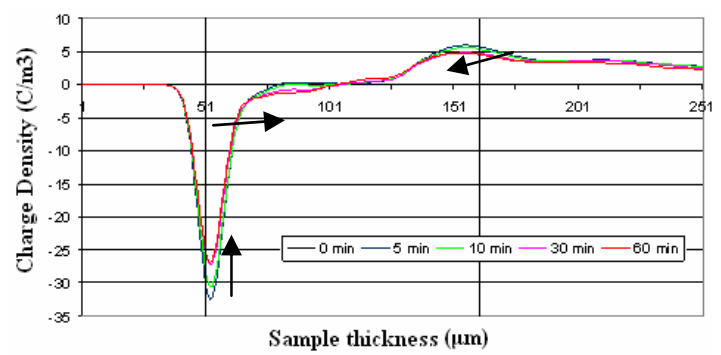

(a) $4 \mathrm{kV}$

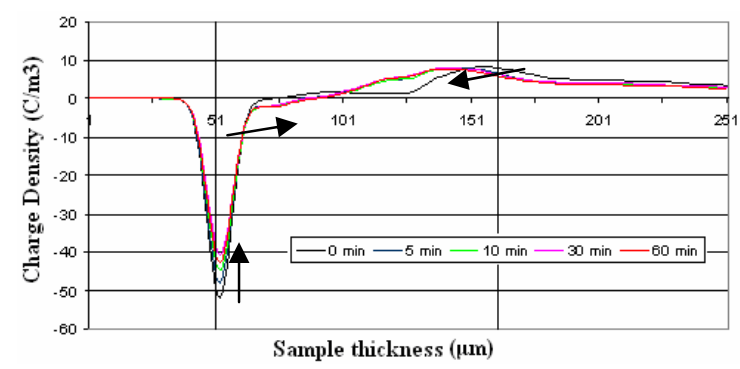

(b) $6 \mathrm{kV}$

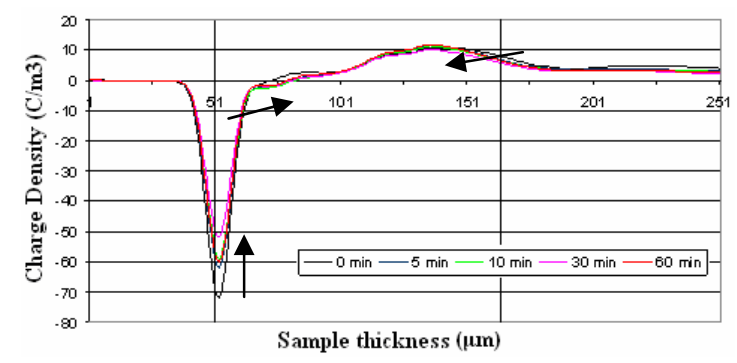

(c) $8 \mathrm{kV}$

Figure 4. Space charge dynamics at different dc electric fields (volts-on at 20 $\left.{ }^{\circ} \mathrm{C}\right)$.
The charge injection deepens into the bulk with the increase of the applied voltage. Under $4 \mathrm{kV}$, homocharges of each polarity enter no more than one layer. Under $6 \mathrm{kV}$, homocharges of each polarity enter more than one layer, it is possible that a small quantity neutralized in the middle layer. Under $8 \mathrm{kV}$, some homocharges reach the layer near to the opposite electrode.

Along with charge injection, the electrode peaks move slightly towards the inner sample direction, especially for the anode peak. There is less negative charge observed in the region adjacent to the cathode. There may be two reasons for this phenomenon. Firstly, compared to positive charge, the amount of negative charge injection didn't increase as much as positive charge with the applied voltage, which indicates that negative charge may travel faster and with less blocked, and it reaches the anode quickly or is neutralized on the way. Secondly, the PEA technique only shows the net charge, the injected charge may be present together with the positive charge which is blocked at the interfaces.

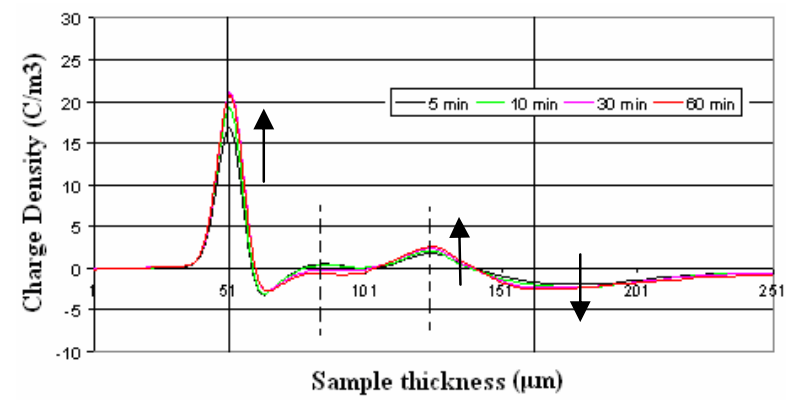

(a) $4 \mathrm{kV}$

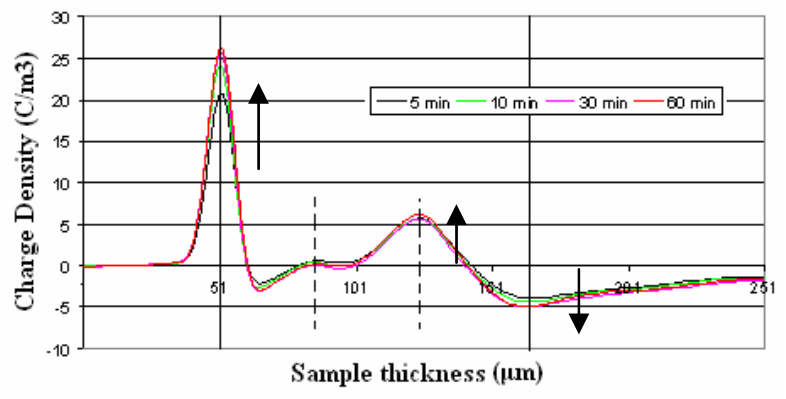

(b) $6 \mathrm{kV}$

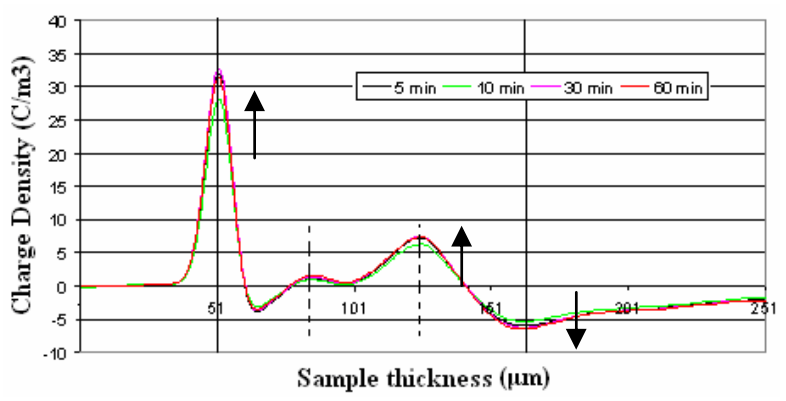

(c) $8 \mathrm{kV}$

Figure 5. Space charge dynamics at different dc electric fields (volts-off at 20 ${ }^{\circ} \mathrm{C}$ ).

Theoretically, in a PEA figure, the integral area of positive peaks is basically the same as that of negative peaks. However, because of the severer acoustic signal scattering in oil-paper 
sample and the contribution of pulse, the test results are somehow different from that from the theory. Besides, because of the deviation in paper thickness, the position of electrodes shown in test results are not exactly the same, which will not effect the final analysis. It is worth stressing that the shape of the charge profile image is not the same for the two electrodes, being broader on the electrode further away from the detector (the anode, right side), for the signal related to acoustic waves having travelled through the whole insulation thickness.

\subsubsection{VOLTS-OFF}

For an early description, charges can be roughly classified as fast and slow charges [10]. 'Slow' charges are those which are essentially trapped in deep traps while 'fast' charges are those which escape from the traps very shortly after the dc voltage is removed. Charges trapped in the insulating material are often stable, i.e. slow charge. The volts-on measurement includes contributions from both fast and slow charges while the volts-off measurement involves mainly slow charges.

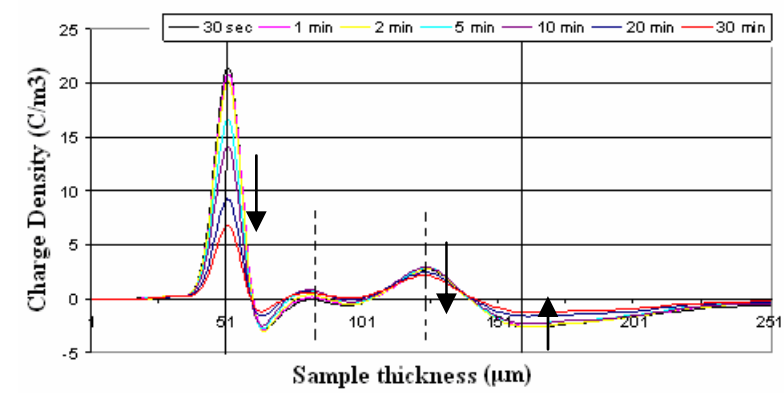

(a) $4 \mathrm{kV}$

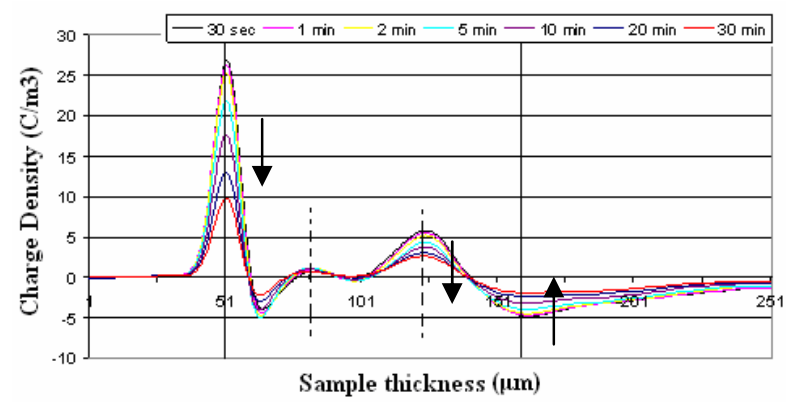

(b) $6 \mathrm{kV}$

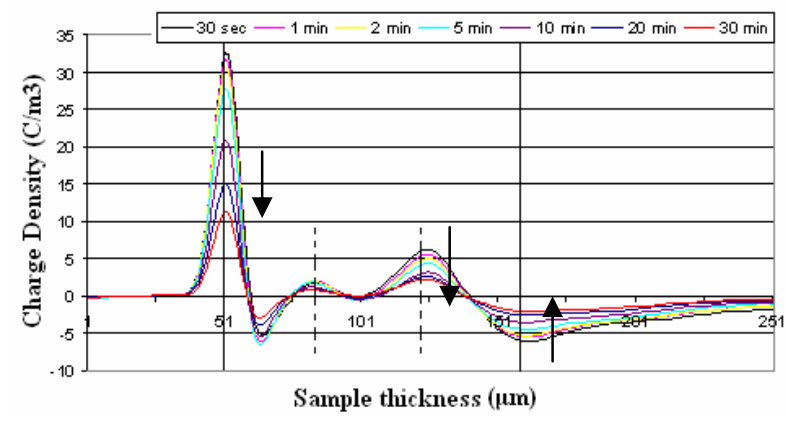

(c) $8 \mathrm{kV}$

Figure 6. Space charge decay after dc electric stressing $\left(20^{\circ} \mathrm{C}\right)$.

After volts-on tests, slow charge distributions for threelayer samples under volts-off condition have been taken as shown in Figure 5. The charge distributions in the bulk hardly changes, while the induced charges form on both electrodes which confirm the homocharge injection happened there under volts-on condition. What's more, the induced charge density on the cathode increases gradually with the increase in the applied voltage (Figures $6 \mathrm{a}, 6 \mathrm{~b}$ and $6 \mathrm{c}$ ), from a maximum of $21 \mathrm{C} / \mathrm{m}^{3}(4 \mathrm{kV})$ to $26 \mathrm{C} / \mathrm{m}^{3}(6 \mathrm{kV})$ and then $33 \mathrm{C} / \mathrm{m}^{3}(8 \mathrm{kV})$, which reflects the increase of charge injection.

Figure 5 also shows that positive charges are dominant in the bulk after the removal of the applied voltage. It is noteworthy that only positive charges appears at the sample layer interfaces, which means the oil-paper layer interfaces act as a barrier for positive charges only. The characteristic is very different from that observed with polyethylene to polyethylene interface [8].

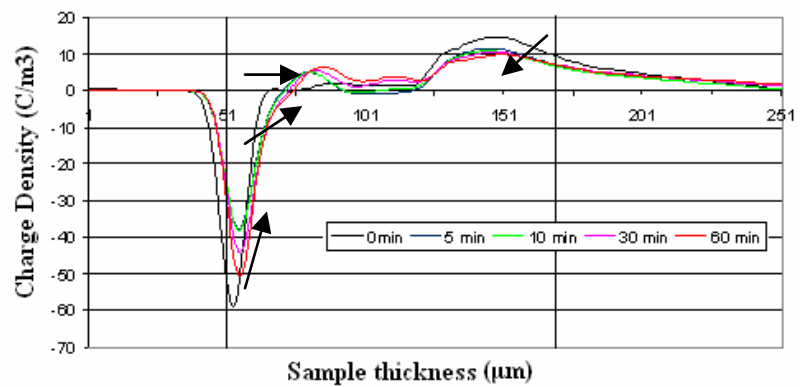

(a) $4 \mathrm{kV}$

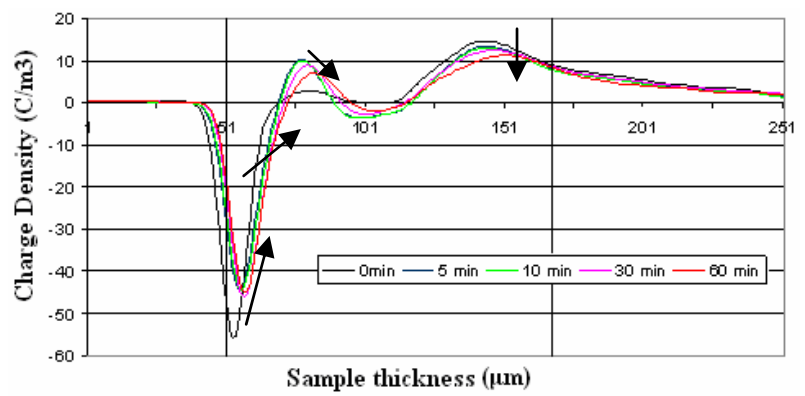

(b) $6 \mathrm{kV}$

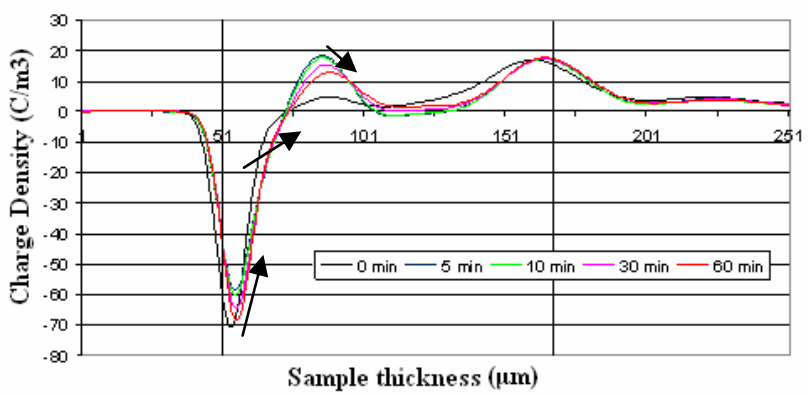

(c) $8 \mathrm{kV}$

Figure 7. Space charge dynamics at different dc electric fields (volts-on at 40 ${ }^{\circ} \mathrm{C}$ ).

\subsubsection{DECAY}

After $1 \mathrm{~h}$ of dc stress, space charge distributions after the removal of the applied voltage are shown in Figure 6 . Compared to volts-on tests where charges are more easily injected into the system, the charge movement under shortcircuit condition is relatively slow. The charge decay speed becomes much slower with the time increase. After $30 \mathrm{~min}$, 
about a quarter of space charges remains in the sample. Further tests indicate that about $90 \%$ charges disappear after 2 h.

The slow decay may be related to the positive charge at the interfaces. As mentioned in the previous section, the interfaces act as a barrier to trap positive charge, limiting the movement of positive charge. The presence of positive charge further affects the negative charge decay.

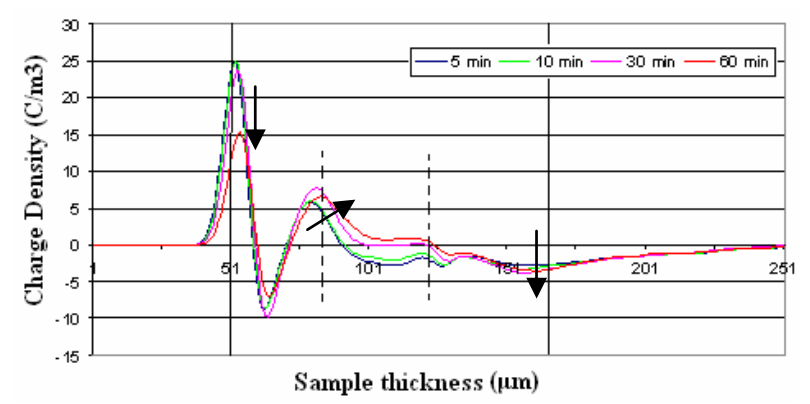

(a) $4 \mathrm{kV}$

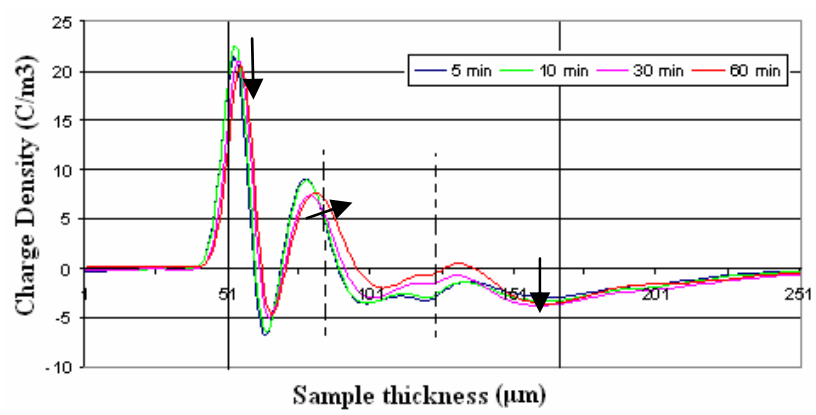

(b) $6 \mathrm{kV}$

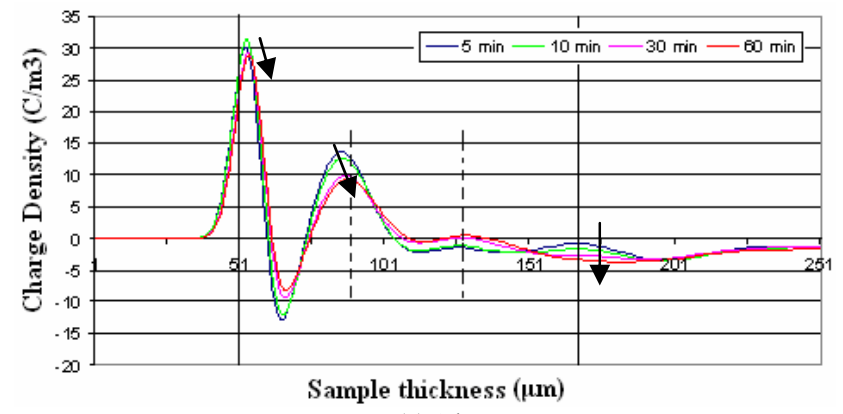

(c) $8 \mathrm{kV}$

Figure 8. Space charge dynamics at different dc electric fields (volts-off at 40 $\left.{ }^{\circ} \mathrm{C}\right)$.

\subsection{PEA TESTS AT $40^{\circ} \mathrm{C}$ 3.3.1 VOLTS-ON}

The space charge dynamics of volts-on at different dc electric fields are shown in Figure 6 after the test temperature was increased to $40{ }^{\circ} \mathrm{C}$. As we can see, the temperature has significant effect on space charge behavior, compared to 20 ${ }^{\circ} \mathrm{C}$, the charge density on the electrodes increases at $40{ }^{\circ} \mathrm{C}$. As expected, the homocharge injection takes place from both anode and cathode under three applied voltages.

At $4 \mathrm{kV}$ (Figure 7a), homocharge injection from the electrodes takes place upon the voltage application, then charges move to the bulk of oil-paper sample. After 5 minutes dc stressing, positive charges have already reached and begun to accumulate at the oil-paper layer interface near to the cathode, and the peak value of charge density there is about $6.0 \mathrm{C} / \mathrm{m}^{3}$ after 60 minutes dc stressing.

At $6 \mathrm{kV}$ and $8 \mathrm{kV}$ (Figure $7 \mathrm{~b}$ and 7c), once the applied voltage was on, homocharges inject very fast into the oilpaper and positive charges move quickly towards the layer interface near to the cathode. More charges injected compared to $4 \mathrm{kV}$, during dc stressing, the peak value of charge density in the oil-paper layer interface near to the cathode increases to $10 \mathrm{C} / \mathrm{m}^{3}(6 \mathrm{kV})$ and $18 \mathrm{C} / \mathrm{m}^{3}(8 \mathrm{kV})$.

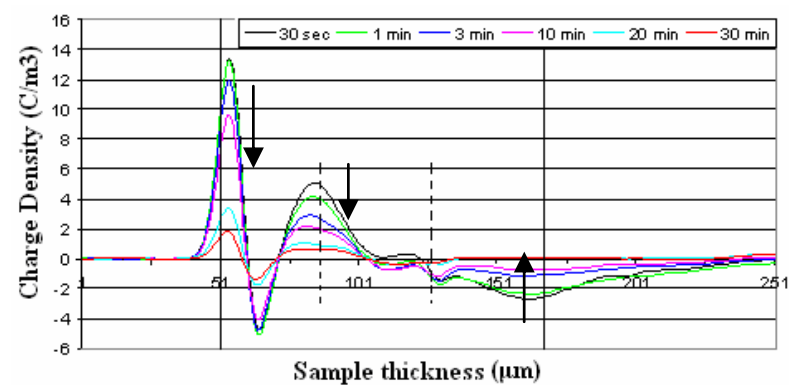

(a) $4 \mathrm{kV}$

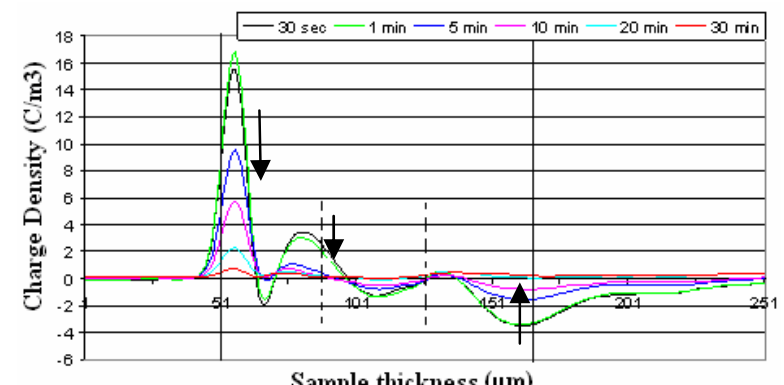

(b) $6 \mathrm{kV}$

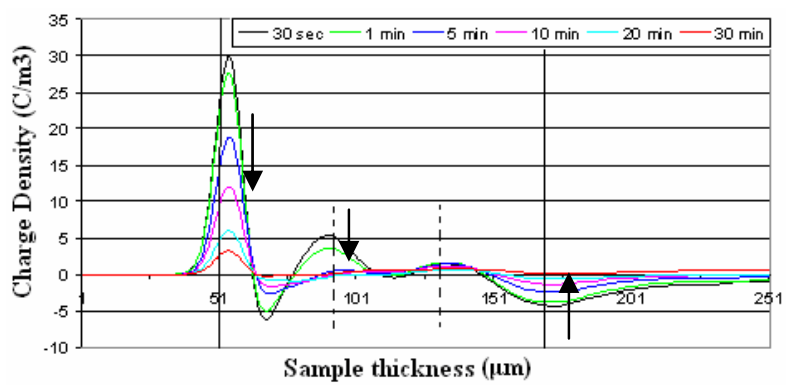

(c) $8 \mathrm{kV}$

Figure 9. Space charge decay after dc electric stressing $\left(40^{\circ} \mathrm{C}\right)$.

The effect of temperature on charge dynamics has two-fold. On the one hand, the injected charges move fast due to mobility increase. On the other hand, space charges gain more energy that they can conquer the restraint of the first oil-paper layer interface near to the anode and travel towards the second layer interface.

Apart from the charge magnitude, the distribution of space charge inside the oil-paper samples is hardly changed with the increases of the applied voltage.

\subsubsection{VOLTS-OFF}

The space charge profiles of volts-off at different dc voltages are shown in Figure 8. Though it can only reflect the behavior of slow moving charges, it confirms the observations obtained from volts-on condition. Firstly, the homocharge 
injection, which can be proved by direct observation of the presence of both negative and positive charge and their locations. Secondly, the accumulations of positive charges in the oil-paper layer interface near to the cathode. More importantly, the negative charge injects from the cathode is clear to be seen. These charges change the internal field distribution and accumulated energy around charged centers, which are thought to be the origin of material degradation [11]

\subsubsection{DECAY}

Space charge behaviors after the removal of the applied voltage are shown in Figure 9. At $40{ }^{\circ} \mathrm{C}$, more than $90 \%$ charges decay after removing the applied voltage for $30 \mathrm{~min}$, which is much faster than that at $20^{\circ} \mathrm{C}$.

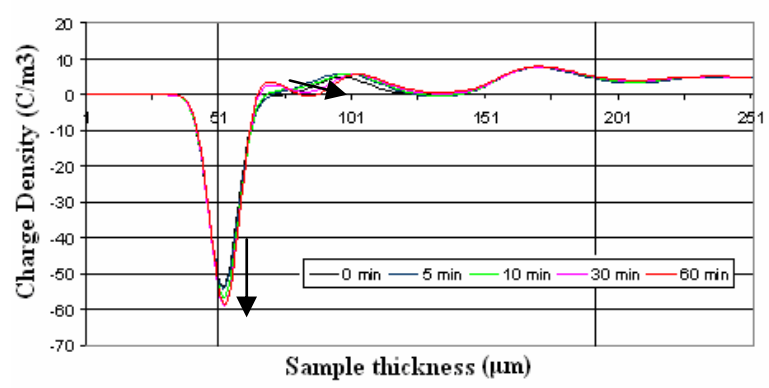

(a) $4 \mathrm{kV}$

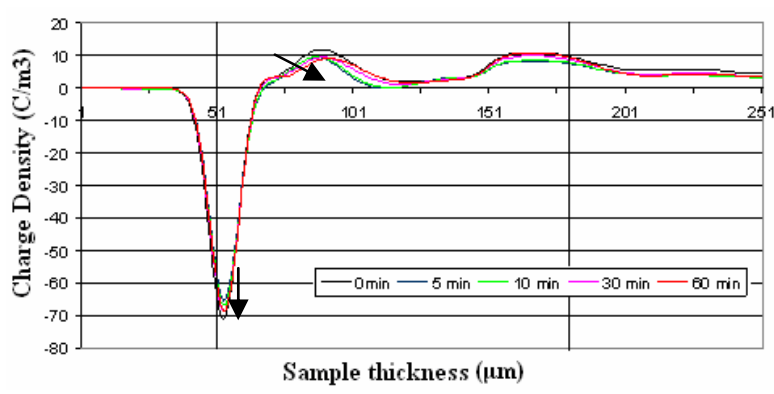

(b) $6 \mathrm{kV}$

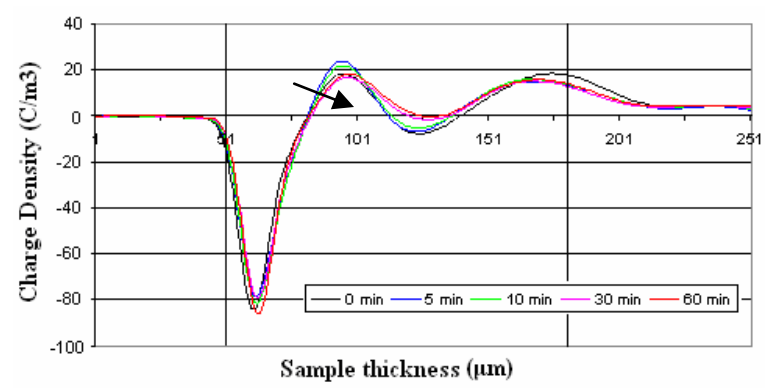

(c) $8 \mathrm{kV}$

Figure 10. Space charge dynamics at different dc electric fields (volts-on at $\left.60^{\circ} \mathrm{C}\right)$.

\subsection{PEA TESTS AT $60^{\circ} \mathrm{C}$ \\ 3.4.1 VOLTS-ON}

When the testing temperature was increased to $60{ }^{\circ} \mathrm{C}$, space charge measurements were done under different applied voltages as shown in Figure 10. Similar to the situation at 20 ${ }^{\circ} \mathrm{C}$ and $40{ }^{\circ} \mathrm{C}$, homocharge injection from both electrodes are observed. It is noteworthy that the positive charges move extremely fast at $60{ }^{\circ} \mathrm{C}$. Significant amount of positive charges have already accumulated at the layer interface near to the cathode on the application of voltage, and no much increase in the charge density happened there in the next 60 minutes de stress. The time for space charge to reach its saturation (steady-state equilibrium) distribution is a practical method to describe the charge accumulation rate [12]. Therefore, the increase in test temperature leads to the increase of the charge accumulation rate, as it shortens the time for space charge reaching to its saturation.

\subsubsection{VOLTS-OFF}

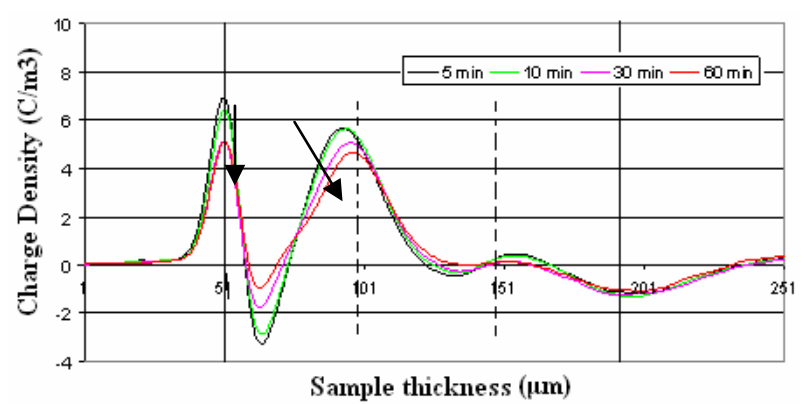

(a) $4 \mathrm{kV}$

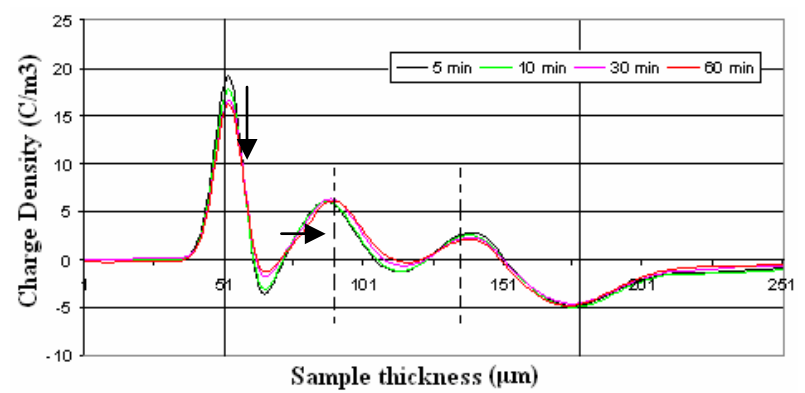

(b) $6 \mathrm{kV}$

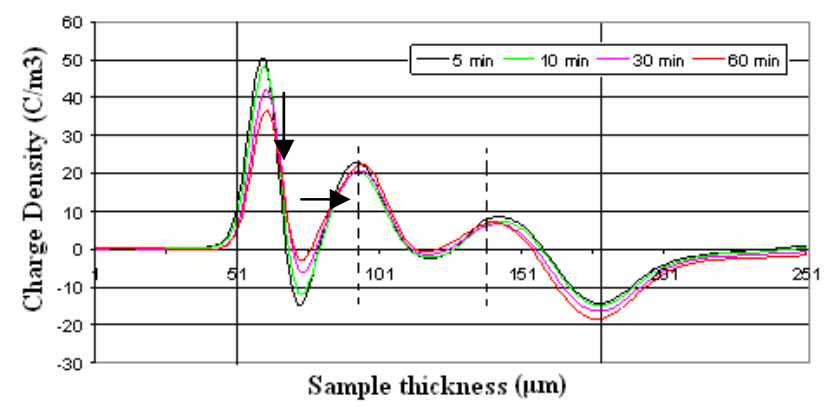

(c) $8 \mathrm{kV}$

Figure 11. Space charge dynamics at different dc electric fields (volts-off at $\left.60^{\circ} \mathrm{C}\right)$.

At $60{ }^{\circ} \mathrm{C}$, the distribution of space charges inside the oilpaper sample is formed at the very beginning, the dc stressing only effects the amount of charge injection, and this is similar to that observed at $20^{\circ} \mathrm{C}$ and $40^{\circ} \mathrm{C}$. However, from the voltsoff test results, it is clear that different temperature will result in different charge distribution. In Figure 11, positive charges accumulate mostly at the layer interface near to the cathode, which is also observed at $40{ }^{\circ} \mathrm{C}$. At the same time, some positive charges are accumulated in the layer interface near to the anode, and they get more and more when the applied 
voltage was increased, the peak value of charge density there after 60 minutes dc stressing increased from about $0.3 \mathrm{C} / \mathrm{m}^{3}(4$ $\mathrm{kV})$ to $3.5 \mathrm{C} / \mathrm{m}^{3}(6 \mathrm{kV})$, and finally to $8.0 \mathrm{C} / \mathrm{m}^{3}(8 \mathrm{kV})$.

\subsubsection{DECAY}

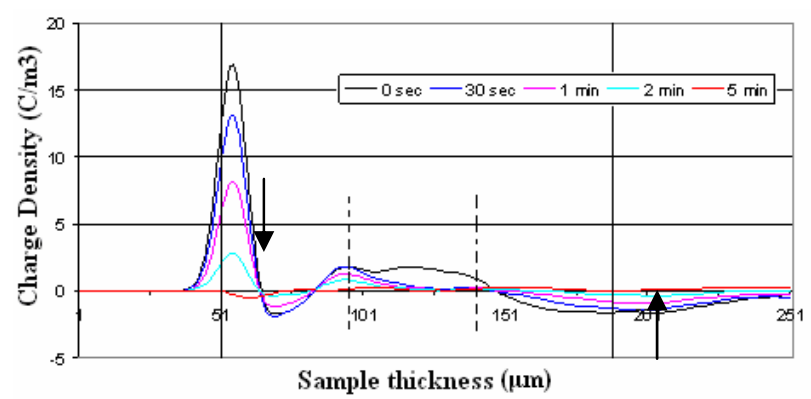

(a) $4 \mathrm{kV}$

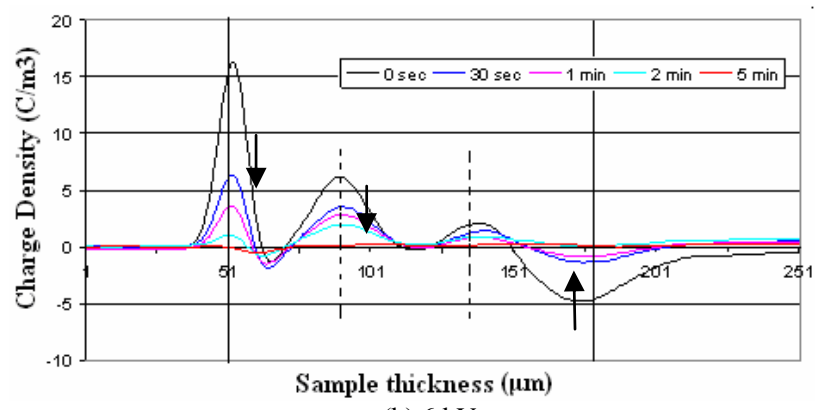

(b) $6 \mathrm{kV}$

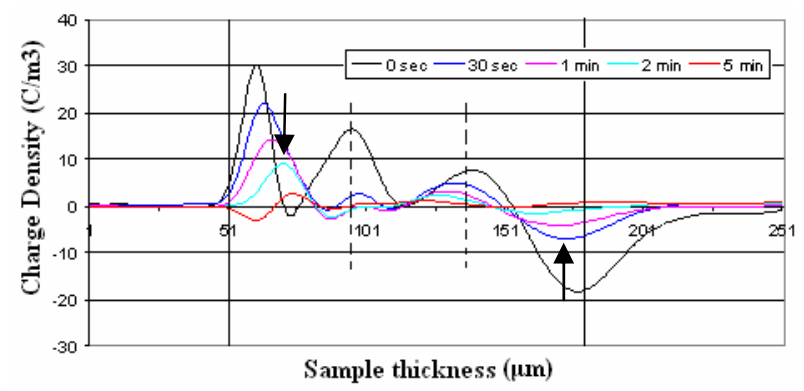

(c) $8 \mathrm{kV}$

Figure 12. Space charge decay after dc electric stressing $\left(60^{\circ} \mathrm{C}\right)$.

In most cases the space charge decay rate corresponds to its accumulation rate, i.e. the faster the space charge accumulates, the faster it decays, or vice versa [12]. Typical results which support this conclusion are presented in Figure 12. Charge decays much faster than that at $20{ }^{\circ} \mathrm{C}$ and $40{ }^{\circ} \mathrm{C}$, and almost all the space charge injected in the oil-paper sample diminishes in 5 minutes after removing the applied voltage, only a little bit charges caused by pulse is observed.

\section{DISCUSSIONS}

\subsection{EFFECT OF POLARIZATION ON POLAR GROUP}

As we know, the chemical components of mineral insulating oil including about $60 \%$ saturated hydrocarbon, $10 \% \sim 30 \%$ naphthenic hydrocarbon, 5\% 10\% unsaturated aromatic hydrocarbon, as well as some other high-molecular compounds such as organic acids, sulfuret, nitride. The power transformer insulating paper is made up of cellulose $(89 \% \sim 90 \%)$, hemicellulose $(6 \% \sim 8 \%)$ and lignin $(3 \% \sim 4 \%)$ [13-14]. The cellulose has a linear polysaccharide consisting of many anhydro D-glucopyranose units linked to each other via 1-4 glycosidic bonds to form polymeric chains [15]. There are many polar groups in oil-paper compounds which are easily polarized under high electrical field.

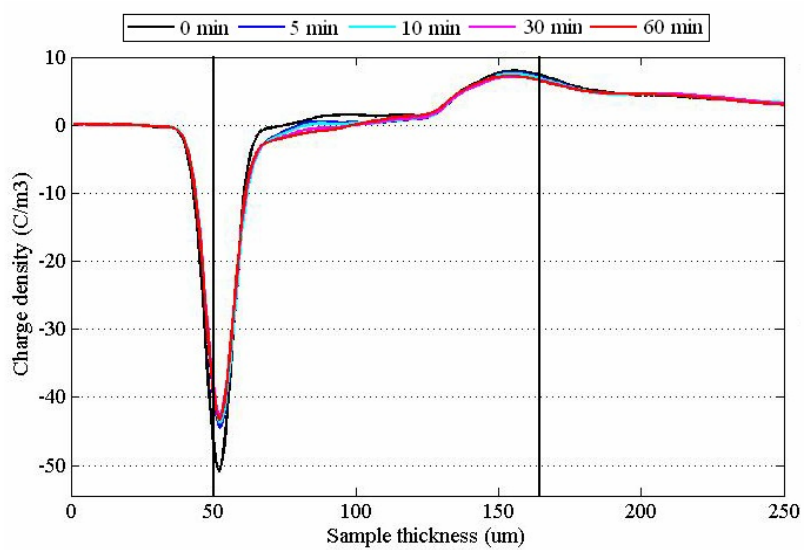

(a) volts-on

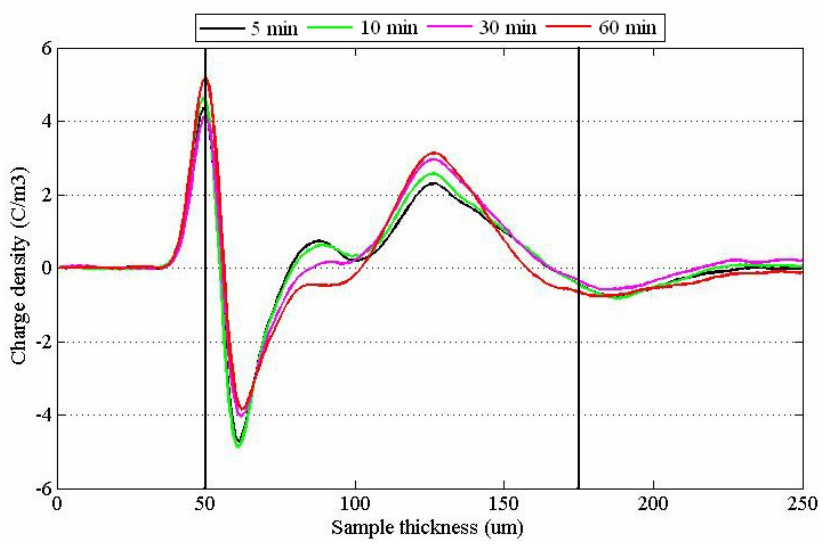

(b) volts-off

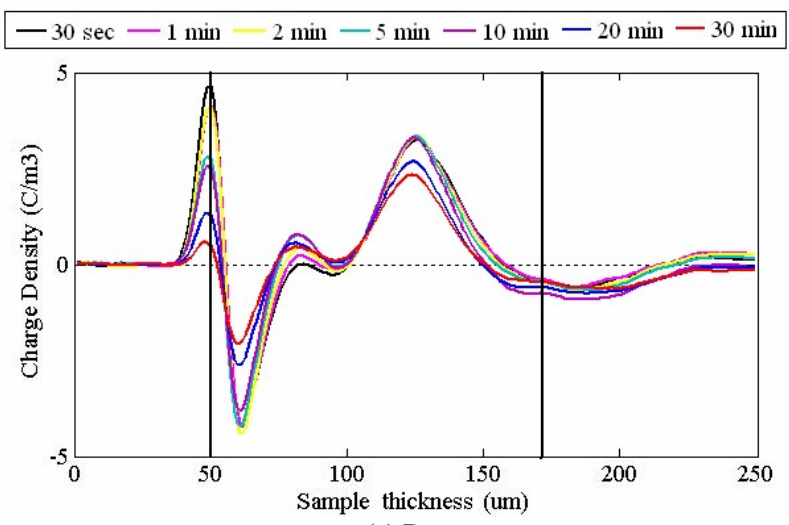

(c) Decay

Figure 13. Space charge figures after getting rid of the global polarization $\left(20^{\circ} \mathrm{C}, 4 \mathrm{kV}\right)$.

It can be assumed that dipoles take the same distribution than the electric field inside the specimen so they produce equivalent charges with more or less the same distribution than space charges. It is not possible to discriminate these two 
types of charges in a measurement. However at the interfaces, dipoles and charges produce very different behaviors that can be decoupled in the measurement. Indeed charges close to an interface produce two peaks, image charge peak and space charge peak, whereas dipoles produce only image charge peak. If there were only charges inside the specimen, the voltage deduced from two integrations over space would not change (applied voltage), even if the charge distribution evolves in time. On the contrary if there were dipoles inside the specimen, the voltage deduced from two integrations over space would evolve and would no longer correspond to the applied voltage.

Hereafter there is a rapid analysis on the PEA test results at $20{ }^{\circ} \mathrm{C}$ to emphasize that fact. After using a MATLAB program to get rid of the global polarization in the raw PEA data, three new figures were obtained as showed in Figure 13.

As we can see in Figure 13a, compared with Figure 4a, during volts-on test, the evolution of the signal between the peaks has not been affected so much by the correction whereas peak amplitudes decrease more slowly due to the charges only.

In Figure 13b, compared with Figure 5a, under short-circuit condition, charge density on the two electrodes decreased a lot, the maximum value decreased from $22 \mathrm{C} / \mathrm{m}^{3}$ to $5 \mathrm{C} / \mathrm{m}^{3}$ on the cathode and from $4 \mathrm{C} / \mathrm{m}^{3}$ to $1 \mathrm{C} / \mathrm{m}^{3}$ on the anode. However, no big changes in charge density and charge distribution observed in the bulk.

After the removal of the applied voltage, space charge behaviors are shown in Figure 13c. Compared with Figure 6a, the same conclusion as above obtained. On the two electrodes, the maximum value of charge density decreased from $22 \mathrm{C} / \mathrm{m}^{3}$ to $5 \mathrm{C} / \mathrm{m}^{3}$ on the left electrode (cathode) and from $4 \mathrm{C} / \mathrm{m}^{3}$ to 1 $\mathrm{C} / \mathrm{m}^{3}$ on the right electrode (anode), while hardly changed in the bulk.

As for the PEA results showed in Figure 13, once the voltage is applied on oil-paper sample, the dipolar polarization may take place in the insulating oil, especially in the interfaces between sample and electrodes. Due to the contribution of polarization, in the position of the cathode, the polarization in oil-paper sample made the charge density under short-circuit condition increased greatly. Theoretically speaking, the charge density on the anode should have the same magnitude. However, because of the attenuation and dissipation of acoustic waves while travelling through the whole insulation thickness, the charge density in the anode is far lower than that on the cathode. Consequently, the integration of the charge density between the two electrodes over time is not zero, even though the signal is acquired under short-circuit conditions.

It is worth stressing that because of the spatial resolution limitation of the PEA equipment used in this paper, the polarization charge inside the sample can not be detected. Therefore, the space charge inside the oil-paper sample is dominated by charge injection, and no changes observed in the bulk after getting rid of the global polarization. It is sensible to analyze the kinetic process of space charge inside the oil-paper sample by charge injection and extraction.

However, this brief analysis demonstrates the importance of dipoles in the analysis of space charge evolution of oil-paper insulation. More precise calculations are required and will be present in future papers.

\subsection{EFFECT OF TEMPERATURE AND THE APPLIED VOLTAGE DURING VOLTS-ON}

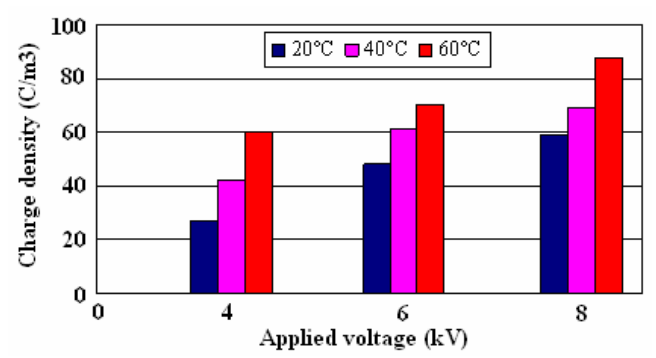

Figure 14. Charge density at the cathode (volts-on $60 \mathrm{~min}$ ) vs the applied voltages under different temperatures.

Considering the peak value of charge density at the cathode on the volts-on $60 \mathrm{~min}$ (Figure 14), both the applied voltage and testing temperature have great effect on charge density at the cathode, the same may happen at the anode as well, though not so obvious due to acoustic scattering and attenuation in oil-paper insulation system. In general, at a relatively low temperature $\left(20{ }^{\circ} \mathrm{C}\right)$, the applied voltage has a greater influence on the charge density. However, with temperature increasing, the influence becomes weak gradually. But when it comes to $60{ }^{\circ} \mathrm{C}$ and the applied voltage is $8 \mathrm{kV}$, the charge density gets the maximum value. It indicates that the combination of high temperature and electrical stress will bring fatal impacts on the performance of oil-paper insulation system.

\subsection{ELECTRICAL FIELD AT VOLTS-OFF}

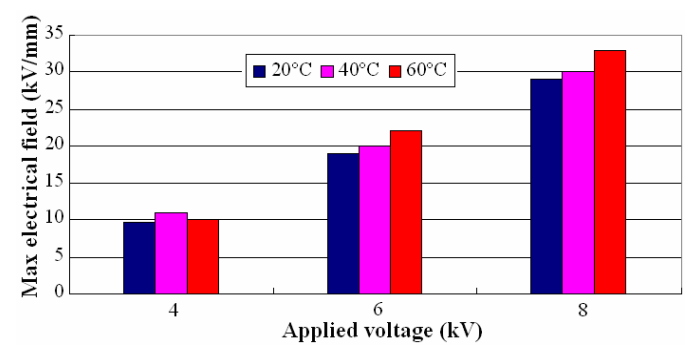

Figure 15. Max electrical field during volts-off.

It was observed that the polarity of the space charge remaining in the bulk was predominantly positive in most cases. The test results show that both negative and positive charge can be injected into oil-paper samples but a large amount of positive charge is trapped as space charge at the interfaces. Along with charge accumulation in the bulk, the electric field inside the sample changed. The electric field distribution in the sample due to trapped charge can be calculated by integrating the charge density [8]. As the position of maximum point of the electric field is variable, which is effected by test temperature and applied voltage, only the maximum value is discussed. 


$$
E(x)=\int_{0}^{x} \frac{\rho(x)}{\varepsilon_{0} \varepsilon_{1}} d x \quad 0 \leq x \leq d
$$

where $\rho(x)$ is the charge density, $\varepsilon_{0}$ is the dielectric constant of vacuum, $\varepsilon_{1}$ is the dielectric constant of test sample.

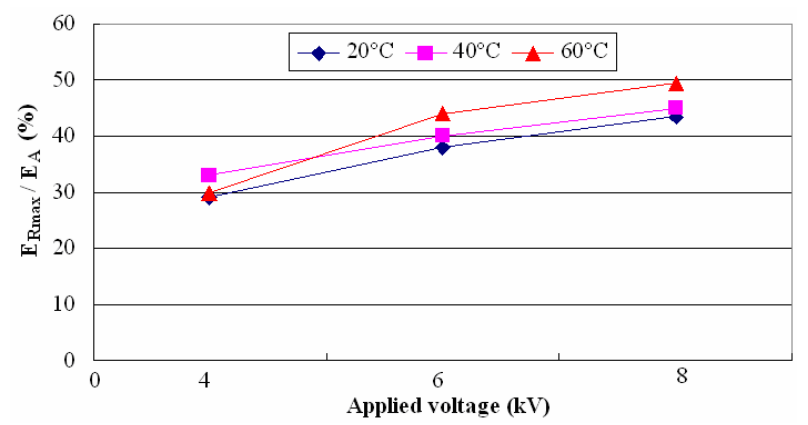

Figure 16. The proportion of max electrical field during volts-off in applied electrical field.

When no voltage applied in the sample, the electric field is almost zero. During electrical stressing, charges inject into the sample and accumulate at the layer interfaces, which lead to the relatively high electric field in the sample even after power off. According to equation (1), the max electrical field at different temperatures and applied voltages during volts-off are summarized in Figure 15. At the same temperature, the residual field after power off increases with the increase of applied voltage. This is mainly because of the increase in the charge injection. The effect to the residual electric field caused by temperature is relatively small. However, at different temperature, as the depth of the charge injection changes, the position of positive charge accumulation is different as well, result in the position change of maximum value of residual field. The proportion of the max electrical field during volts-off in relation to the applied electric field is shown in Figure 15. $E_{R \max }$ is the maximum residual electrical field in the bulk, $E_{A}$ is the applied electrical field during volts-on. It is noteworthy that the maximum value of residual field in volts-off at $8 \mathrm{kV}$ increases to about $33 \mathrm{kV} / \mathrm{mm}$, which is close to $50 \%$ of the applied electric field (Figure 16). As we know, a high local electric field can lead to partial discharge activity, resulting in acceleration of degradation processes, degradation of the material and possibly premature failure of the insulation system [16, 17]. Especially for the converter transformer, a high residual electrical field will lead to fatal damage during polarity reversal operation.

\subsection{DECAY TIME}

The time dependent decay of the accumulated space charge after short circuiting is of major importance in insulating materials intended for dc applications, as it defines the amount of time the charge can be retained for, and hence the effect that retained charge can have when the electric potential is again applied [18].

Figure 17 shows the maximum value of charge density in the bulk as a function of the decay time. The decay rate can be obtained from the slope. At a given temperature, these rates were much larger when the applied voltage was larger. In addition, the testing temperature has a significant effect on the decay rate. Decay rate at $60{ }^{\circ} \mathrm{C}$ is much faster than that at 20 ${ }^{\circ} \mathrm{C}$ and $40{ }^{\circ} \mathrm{C}$ as expected.

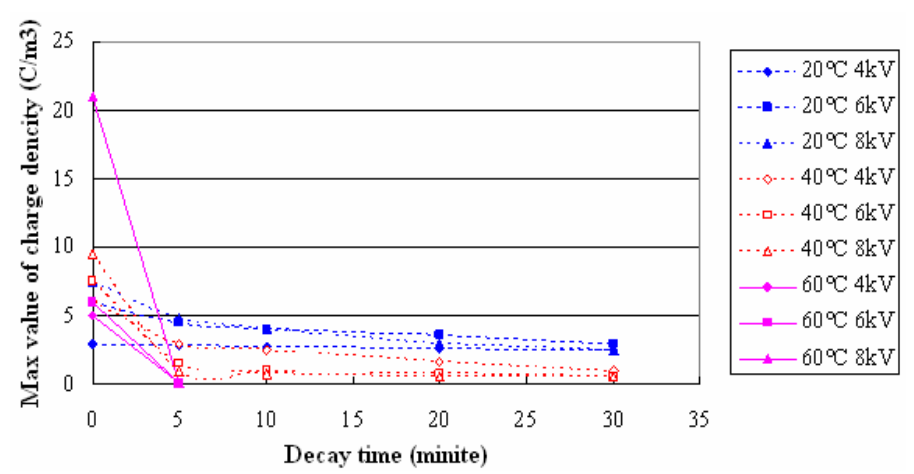

Figure 17. Max value of charge density in the bulk versus decay time.

These results also suggest that the charge decay in oil-paper sample may be influenced by the electric field produced by the accumulated space charge in the bulk. Therefore there is significant probability that the field produced by the accumulated space charge distribution after short-circuiting affects the decay of the space charge trapped in the bulk. Since the space charge is located in the bulk of the sample, decay is probably governed by transit of the charge to the electrodes for neutralization, which will be facilitated by high space charge fields and high temperatures.

\section{CONCLUSIONS}

In this paper, the PEA measurements on multi-layer oilimpregnated insulation paper samples were presented. Space charge dynamics under volts-on, volts-off and decay conditions are analyzed. The conclusions are summarized as follows:

(1) Once the external voltage is applied across the sample, homocharge injection takes place under all the test conditions.

(2) Positive charges are found to be dominant in the amount, and they tend to accumulate at the layer interfaces, and increase with increasing applied voltage. This indicates that the oil-paper layer interfaces act as a barrier for positive charges. This will effect the distribution of electrical field and deteriorate the electrical behavior of oil-paper insulation.

(3) The amount of injected charge, charge mobility and charge distribution in oil-paper insulation are affected by the applied dc voltage and temperature. As far as the results showed in this paper are concerned, the applied dc voltage mainly affects the amount of space charge, while the temperature has greater influence on the distribution and mobility of space charge inside oil-paper samples.

(4) The decay rate of space charge increases with the increase of the applied voltage. In addition, the testing temperature has a significant effect on the decay rate. Moreover, space charge injected in the bulk of the sample which results in the electric field distortion will have some influence on the charge decay. 
(5) Once the voltage is applied on oil-paper sample, the dipolar polarization may take place in the insulating oil, especially in the interfaces between sample and electrodes. The importance of dipoles in the analysis of space charge evolution of oil-paper insulation must be realized.

\section{ACKNOWLEDGEMENT}

One of the authors (Chao Tang) wishes to thank the 'Chinese Scholarship Council Funding for Joint Training $\mathrm{PhD}$ Student' and the Chinese National basic research program of china (973 program) (2009CB724505-1) for the financial support provided.

All authors wish to thank Dr. Stéphane Holé for his contribution on the explanation of polarization effect in oilpaper samples.

\section{REFERENCES}

[1] Y. Zhang, J. Lewiner, C. Alquie and N. Hampton, "Evidence of strong correlation between space charge buildup and breakdown in cable insulation", IEEE Trans. Dielectr. Electr. Insul., Vol. 3, pp. 778-783, 1996.

[2] Z. Liu, R. Liu, H. Wang and W. Liu, "Space charge and initiation of electrical trees", IEEE Trans. Dielectr. Electr. Insul., Vol. 24, pp.83-89, 1989.

[3] G. Mazzanti, G. C. Montanari and J. M. Alison, "A space-charge based method for the estimation of apparent mobility and trap depth as markers for insulation degradation-theoretical basis and experimental validation", IEEE Trans. Dielectr. Electr. Insul., Vol. 10, pp. 187-197, 2003..

[4] P. Morshuis and M. Jeroense, "Space charge measurements on impregnated paper: a review of the PEA method and a discussion of results", IEEE Electr. Insul. Mag., Vol. 13, No. 3, pp. 26-35, 2003.

[5] P. Morshuis, M. Jeroense, "Space charge in HVDC cable insulation", IEEE Conf. Electr. Insul. Dielectr. Phenomena (CEIDP), Minneapolis, USA, Vol. 1, pp. 28-31, 1997.

[6] R. Ciobanu, C. Schreiner, W. Pfeiffer and B. Baraboi, "Space charge evolution in oil-paper insulation for DC cables application", IEEE 14th Intern. Conf. Dielectr. Liquids (ICDL), Massachusetts, USA, pp. 321-324, 2002.

[7] G. Chen, M. Fu, X. Z. Liu and L. S. Zhong, "Ac aging and space-charge characteristics in low-density polyethylene polymeric insulation”, J. Appl. Phys., Vol. 97, pp. 1-7, 2005.

[8] G. Chen, Y. Tanaka, T. Takada and L. Zhong, "Effect of polyethylene interface on space charge formation", IEEE Trans. Dielectr. Electr. Insul., Vol. 11, pp. 113-121, 2005.

[9] R.C. Ciobanu, W. Pfeiffer and C. Schreiner, "Charge packet evolution in paperoil insulation and derived technological considerations", 7th Intern. Conf. Properties and Applications of Dielectric Materials, Vol. 2, pp. 695-698, 2003.

[10] G. Chen, Y. L. Chong and M. Fu, "Calibration of the pulsed electroacoustic technique in the presence of trapped charge", Measurement Science and Technology, Vol. 17, pp. 1974-1980, 2006.

[11] J. Li, Y. Zhang, Z. Xia, X. Qin and Z. Peng, "Action of space charge on aging and breakdown of polymers", Chinese Science Bulletin, Vol. 46, pp. 796-800, 2001.

[12] M. Fu, G. Chen, L. A. Dissado and J. C. Fothergill, "Influence of thermal treatment and residues on space charge accumulation in XLPE for DC power cable application", IEEE Trans. Dielectr. Electr. Insul., Vol. 14, pp. 53-64, 2007.

[13] A. D. Pablo and B. Pahlavanpour, "Furanic compounds analysis: a tool for predictive maintenance of oil-filled electrical equipment", Electra, Vol. 175, No. 7, pp. 9-31, 1997.

[14] A. M. Emsley, X. Xiao, R. J. Heywood and M. Ali, "Degradation of cellulosic insulation in power transformers. part 3: effects of oxygen and water on ageing in oil", IEE Proc.: Sci. Measurement Techn., Vol. 147, pp. 115-119, 2000.

[15] Rui-jin Liao, Chao Tang, Li-jun Yang and S. Grzybowski, "Thermal Aging Micro-scale Analysis of Power Transformer Pressboard", IEEE Trans. Dielectr. Electr. Insul., Vol. 15, pp. 1281-1287, 2008.

[16] L. A. Dissado, G. Mazzanti and G. C. Montanari, "Elemental strain and trapped space charge in aging of insulating materials. Part 1: Elemental strain under thermo-electrical-mechanical stress", IEEE Trans. Dielectr. Electr. Insul., Vol. 8, pp. 959-965, 2001.
[17] N. Hozumi, T. Takeda, H. Suzuki and T. Okamoto, "Space charge behavior in XLPE cable insulation under $0.2-1.2 \mathrm{MV} / \mathrm{cm}$ dc fields", IEEE Trans. Dielectr. Electr. Insul., Vol. 5, pp. 82-90, 1998.

[18] S. Mitsumoto, M. Nagao, M. Fu, L. A. Dissado and J. C. Fothergill, "The space charge decay of high density polyethylene under different temperatures and accumulation fields", IEEE Intern. Conf. Solid Dielectr. (ICSD 07), Hampshire, UK, pp. 470-473, 2007.

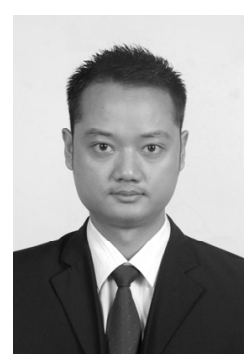

Chao Tang was born in Sichuan, China in 1981. He received the B.Eng. (2004) and M.Sc. (2007) degrees in electrical engineering from Chongqing University, China. Now, he is a Ph.D. candidate in the Electrical Engineering College of Chongqing University, China. From August 2008 to August 2009, as a visiting Ph.D. student, he started the space charge research works of oil-paper insulation in University of Southampton, UK. His research activities are mainly in the field of online monitoring of insulation condition and fault diagnosis for high voltage apparatus.

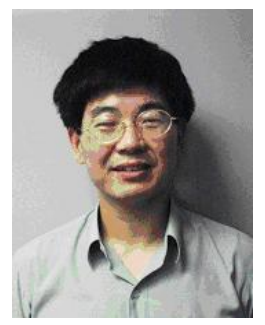

George Chen was born in China in 1961. He received the B.Eng. (1983) and M.Sc. (1986) degrees in electrical engineering from Xi'an Jiaotong University, China. After he obtained the Ph.D. degree (1990) from the University of Strathclyde, UK, on the work of permanent changes in electrical properties of irradiated low-density polyethylene. He joined the University of Southampton as postdoctoral research fellow and became a senior research fellow subsequently. In 1997 he was appointed as a research lecturer and promoted to a Reader in 2002. Over the years, he has developed a wide range of interests in high voltage engineering and electrical properties of materials and published over 150 papers.

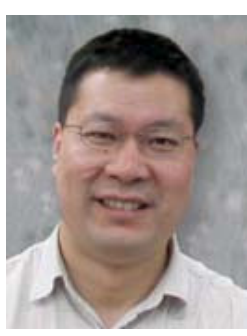

Mingli Fu was born in Shannxi, China in 1962. He received the B.Eng. degree in electrical engineering from Xi'an Jiaotong University, China in 1983. He spent many years at China Electric Power Research Institute (CEPRI) as a Research and Development engineer before he came to UK as a visiting research fellow at the University of Southampton in 1997, and later on obtained the Ph.D. degree from the same university. He was a lecturer at the University of Leicester, UK. He is currently a senior technologist at Areva T\&D Technology Centre in UK. His research interests lie in dielectric materials, high voltage technology and the insulation system ageing and integrity diagnosis.

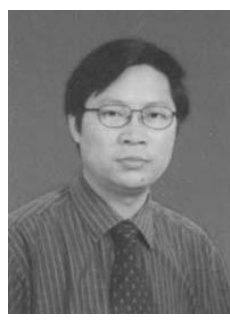

Rui-jin Liao was born in Sichuan, China in 1963. He received the M.S. and Ph.D. degrees in electrical engineering from Xi'an Jiaotong University, China and Chongqing University, China, respectively. Since 1999 he is a professor of Electrical Engineering College at Chongqing University, China. His research activities lie in the field of on-line monitoring of insulation condition and fault diagnosis for high voltage apparatus, as well as aging mechanism and diagnosis for power transformer. He is author/ coauthor of one book and over 80 journal and international conferences. 